\title{
Processes, Issues, AIR: Toward Reticular Politics
}

\section{Michael Dieter}

Politics is active experimentation, since we do not know in advance which way a line will turn.

(Deleuze and Parnet 103)

Conceived and produced by the Preemptive Media collective - a group consisting of interdisciplinary artists and researchers Beatriz da Costa, Jamie Schulte and Brooke Singer-Area's Immediate Reading or AIR (2006) is an ongoing experimental project that invites people to monitor pollution levels in their local urban surroundings using portable air-sensor devices. ${ }^{1}$ Originally carried out in New York City, the AIR project gave participants or 'carriers' specially designed equipment to self-identify the quality of the air they breathe every day, actively tracing dangerous levels of pollutant gases like nitrogen oxide, carbon monoxide and ground level ozone. These chemical compounds, for the most part, have been identified as by-products of carbon combustion, and are directly linked to phenomena like climate change, smog, acid rain and the onset of respiratory illness. While government-based organizations such as the Environmental Protection Agency in the United States (or the National Pollutant Inventory here in Australia) calculate air quality based on highly sensitive readings of these substance emissions (along with sulphur dioxide and particulate matter), their Air Quality Index is produced through fixed monitoring spread over a wide geographic distance. $A I R$ augments such official knowledge by allowing a relatively accurate estimate of an individual's personal intake or exposure within a small area over a short length of time. Although the data remains highly localised, the work of assembling this information provides a context or platform for discussion of health and environmental issues through direct participation. That the atmosphere itself is made explicit as a result of such sampling is a peculiar quality of the techno-scientific techniques used both to expand and to complicate sensation in this hybrid and experimental forum, an open-ended laboratory. The project thus can be claimed to bring about a unique model of political action and assembly: it imbricates a network of actants in a process directed toward the construction of public facts, and renders explicit otherwise unrepresented entities (i.e. particles) as stake-holders in a common situation.

\footnotetext{
${ }^{1}$ See Preemptive Media, AIR; <http://www.pm-air.net $>$
} 
From a theoretical perspective, $A I R$ can be interpreted as working in the register of what Bruno Latour calls Dingpolitik, a densely materialist approach to representational forums in two meanings of the word represent: drawing together legitimate actants around an issue (politics), and presenting a matter of concern, a topos, to those assembled (science) (Latour, 'From Realpolitik to Dingpolitik' 18). Construed as a response to the perceived crisis of contemporary forms of governance, this concept focuses on how emergent, material, collaborative and complex dynamics have become important topics for thinking of new ways of acting politically. In general, Dingpolitik can be seen as marking a shift away from targeted forms of tactical intervention or 'resistance' towards modes of networked assembly, projective action and the participatory assembling of social issues. Here, problems frequently emerge between the structural persistence of these distributed formations (especially their processual or non-representative nature), and the ongoing necessity to account for movement, contingency and change. Quite simply, there remains a question of how to inaugurate broadly collective or participatory action against such highly unstable, entangled and distributed issues such as air quality and environmental health. According to Latour's proposal for democratic reform, we require a new stylistic grammar that can effectively mediate the convergence of political, artistic and technical representations ('What is the Style of Matters of Concern?' 16-32). This article explores the grounds for such an eloquence of reason by outlining its implications for techno-scientific interventions, especially in terms of what political philosopher Noortje Marres calls formatting issues. I suggest that her concept of the issue network is a useful reworking of the democratic impulse of Actor-Network-Theory (ANT) influenced approaches to political action by focusing on the structuration of controversies at the limits of institutional overlap. Here, the $A I R$ project is used as an exemplary case study of sorts, an example that can illuminate links between network experiences; the relations between affective, material and reflexive dimensions of socio-technological ensembles; and our capacities effectively to gauge matters-of-concern.

\section{Reticulation}

Like a great deal of new media art, the work of Preemptive Media openly challenges stable institutional, disciplinary and technological boundaries. As a techno-social experiment, the $A I R$ project operates between several interrelated spheres, being funded by the Eyebeam Gallery and Lower Manhattan Cultural Council, but functioning as a subsidiary to government-based information-gathering through the ethos of open-source technology, peer production and activist-based politics. The experimental features of the work, as a result, emerge not only through the investigation of pollution particles in the atmosphere, but also by the co-joining of participatory deliberation, collaboration and standardised techniques of scientific inquiry. Critically, this 
desire for a polyvocal or hybrid approach to the construction of 'factual knowledge' is increasingly apparent as a concern across of a range of politically-oriented art practices. Indeed, the project lends itself to a reading that emphasizes this dimension of experimental work as an intervention of sorts. The notion of 'tactical biopolitics', for instance, has been proposed as a label for this emergent interdisciplinary field that shares the highly politicised tone of earlier forms of tactical media, but turns to an exploration of the production, distribution and deployment of scientific facts (da Costa and Philip). ${ }^{2}$ This tendency can be observed in the bioart projects of groups like SymbioticA, the Critical Art Ensemble or The Biotech Hobbyist collective; or alternatively, in the specific trend toward confronting issues surrounding climate change addressed in exhibitions such as $A E R$ at the Green Museum in New York or atmos: weather as media at MIC Toi Rerhiko in New Zealand, as curated collections of atmospheric artworks. ${ }^{3}$ While the concept of the biopolitical relates to these investigations as an intensified form of governmentality through techno-scientific, communicative or affective dimensions of 'life' itself, my account is much less invested in debates around the management of populations, than with charting a kind of pragmatics, or a turn toward things and objects evidenced by bioart - what Latour calls pragmata ('From Realpolitik to Dingpolitik' 38). In particular, the materiality of such aesthetics relates to their characteristics as hybrid forums, to their capacity to establish a new style for addressing distant and complex issues by opening techno-scientific, political and art-based practices to the problem of multiplicity.

Crucially, AIR can be described as dealing with the atmosphere as a thing, rather than an object. According to Latour, the difference marked by the term is a shift from discrete, bounded and transparent matters-of-fact to variegated and networked matters-of-concern. Obviously, this idea of mattering takes on a dual meaning, drawing attention both to the materiality and to the competing investments of actants that make up a controversy. However, its main conjecture is to foreground the increasing uncertainty associated with the experience of contemporary everyday life. In this respect, the role of the science as a guarantor of stable knowledge, facts and objects has increasingly been superseded by the visible and widely felt entanglements unleashed by modernity, placing emphasis on contingency and instability as a commonly experienced condition (Beck). This is especially the case where evidence of global warming, atmospheric pollution or climate change remains highly contested or held in question, or where environmental factors are under-defined in public debates. Obviously, these difficulties in confronting ecological crises are partly a result of their intensive and global qualities, through the way in which such phenomena occur

\footnotetext{
${ }^{2}$ For tactical media itself, see also Broeckmann; Critical Art Ensemble; Lovink

${ }^{3}$ See AER website: <http://www.greenmuseum.org/c/aer/> and atmos:

$<$ http://mic.org.nz/events/exhibitions/present/atmos $>$
} 
'at a distance', at levels often well beyond forms of institutional articulation. Environmental issues, as a consequence, can be considered in the register of what John Law describes as emergent complexity - an ontological condition in which interventions shape the object of analysis across an expansive field of relations (Law 1-15). Here, the question is primarily one of confronting the multiple, a situation in which knowledge still remains 'in-the-making' and unbounded by stabilised regimes of power.

If distributed and complex settings have become the signature of the contemporary moment, their prominence coincides with a renewed philosophical interest in processual thought as a pragmatics of becoming. This is apparent in the current significance of ontogenesis for considering states in-formation, for describing 'order out of chaos', or the manner in which entities or public issues are created without resorting to so-called 'cultural laws of positioning and ideology' (Massumi 1-21). While such models are related importantly to affective politics, the notion of a partially under-defined objectivity has additionally led to an analysis of the agential effects of non-human forces; in the case of ANT, to an analysis of techno-scientific practices as 'politics by other means'. From the perspective of Latour, in particular, a demand for the rights of objects can only be made after realising a mutual entanglement of the human and non-human. Here, the social is experienced foremost as a becoming, in the sense of grappling with issues that appear unprecedented, without clear boundaries or demarcations (i.e. 'matters-of-concern'). The distribution of agency between entities is, therefore, registered by taking into account the ongoing uncertainty of such groupings as they come to be represented. This work of assembling, of interconnecting and dispersing - a dynamic that both informs and dissolves meaning or representation - is posited by ANT, in media res, as the opening stage of analysis ('Reassembling the Social' 27). For Latour, 'the network' becomes a kind of medium, or more accurately, a concept that makes legible the actions that contribute toward stable definitions or actualised knowledge. Rather than a pre-defined structure or thing 'out there', the actor-network resembles something closer to the rhizome of Deleuze and Guattari for designating a series of translations or transductions (A Thousand Plateaus 3-25). This sense of relational activity has led to unique ANT-style accounts of laboratory experimentation, urban planning and economics, eventually forming the basis for an overarching critique of the constitution of Western modernity itself (Latour, We Have Never Been Modern). ${ }^{4}$ More importantly, the concept of the network as ontogenetic allowed such innovations precisely by passing over gridlocked binaries of structure and agency to focus on an analytics of movement itself.

\footnotetext{
${ }^{4}$ See also the influential or 'mythical' case studies on microbes, scallops and reefs (Latour Reassembling the Social, 106).
} 
In its own way, techno-scientific projects like $A I R$ work through this ontology: they combine dispersed elements into particular consistencies in order to bring about emergent fields of inquiry. Positioned in relation to the field of new media art, this collective experimentation with scientific facts is specifically based on the translation of peer production models usually associated with software development into contexts that are not abstractly digital or exclusively concerned with the characteristics of code. In particular, the influence of the free software movement as a development based on the collaborative 'tinkering' with distributed technologies, and opening out of black-boxed devices to participatory modification, is a central feature of these practices (Berry). This kind of collective assembling or projective political action is apparent with the $A I R$ project in the form of a networked topography between actants and affordances. By linking environmental sensors, airborne pollutants, GPS (Global Positioning System) tracking devices, individuals as carriers, information visualisations (through the Processing software), Internet-based applications like GoogleEarth and so on, the overall outcome is materially to induce a political effect on an emergent scale, rather than according to pre-formatted technics of deliberation. Indeed, the construction of this work might be understood through the notion of 'media ecology' as a mode of amplifying connectivity and systemic agency - for instance, what Matthew Fuller describes as the capacity for standard objects to transcend their material limits when relationally composed as a process of individuation (Media Ecologies). This notion of linking together technological affordances opens out analysis to consider the various utilitarian protocols that allow for material energies to flow across variegated networks. From an industrial perspective, the shift from a code-based aesthetics of digital objects to an ecological materialism is evidenced by the use of Arduino as an electronics prototyping device based on flexible, easy-to-use programming - an innovation cited in discussions toward open source hardware, infrastructure and architecture (Fuller and Haque). ${ }^{5}$ For the $A I R$ project, the pursuit of political action is not directed by any purist idea of contested resistance, but through an arrangement as a hybrid forum - an assemblage of various agential forces. Pigeonblog, a related endeavour by Beatriz da Costa, Cina Hazegh and Kevin Pronto, takes this approach further by enrolling homing pigeons as carriers of environmental sensors, an example of inter-species co-production of environmental knowledge. ${ }^{6}$

Naturally, a major aspect of the $A I R$ project involves debate and discussion in this exploration of technical devices. Since the aim to raise public awareness of health and environmental degradation occurs through collective techno-scientific action, such discursive components are combined with a critical understanding of informational circulation. As Beatriz da Costa of Preemptive Media explains:

\footnotetext{
5 See Arduino website: <http://www.arduino.cc/>

${ }^{6}$ See $<$ http://www.pigeonblog.mapyourcity.net/>
} 
Activist pursuits can often have a normalizing effect rather than one that inspires social change. Circulating information on 'how bad things are' can easily be lost in our daily information overload. It seems that artists are in the perfect position to invent new ways in which information is conveyed and participation is inspired. (da Costa 379)

Indeed, even the use of informational networks such as blogs and websites is arranged critically to perpetuate the work in components by archiving key techniques, source code, data collected and the standard devices utilised. The openness of the work is based on this connectivity, where the digital becomes simply one vector in a communicative space of interaction, where meaning emerges through both discursive and material energies. Félix Guattari influentially described these forms of 'mixed semiotics' as processes that refer to an ethico-aesthetic paradigm - they facilitate choices, they require decisions at every step, but function thoroughly as enmeshed networks of interaction (assemblages), where every movement resonates throughout a field of similarly responsive forces which feed back, reshaping perception and sense (Guattari 1-32). The ethico-aesthetic is precisely the terrain for developing a style appropriate to matters-of-concern, foregrounding a processual and experimental approach to formulating collective issues that marks a distinct break with representational modes of politics as such. Of course, the $A I R$ project can be formally conceived as a kind of amateur data collection, but its actual significance lies in the participatory work of documenting and formalising this knowledge. While the project relies on institutional structures and technical protocols for support, its operation strives to exceed both as a social platform. I suggest this be seen as a capacity to reticulate, to ally heterogeneous actants into a resonant and open-ended consistency that enables replication and further modification. ${ }^{7}$ As a method of engagement, I want to suggest that reticulation speaks to Dingpolitik by confronting multiplicity through the inauguration of a collective activism.

\section{Formatting issues}

By foregrounding complexity, the trend toward tactical biopolitics or techno-scientific art can broadly be seen as a concern with distributions of agency found in ecological politics. Given the hybrid nature of these emergent practices, however - between institutional and disciplinary formations - there remains a question of how such reticular action might be understood specifically in political terms. In Latour's conception of 'the parliament of things' and 'making things public', the reformation of political forums is largely framed through a democratic paradigm based on the hierarchical and exclusionary composition

\footnotetext{
${ }^{7}$ For instance, Preemptive Media has reproduced the AIR project in capital cities across Australia, the United States and Belo Horizonte, Brazil: <http://www.pm-air.net/>
} 
of governance (Latour, Politics of Nature 128-83). To describe the projects of Preemptive Media primarily as a democratic response to environmental concerns in this mode would seem to conflate central traits of co-emergent and participatory assembly with the procedural abstract logic of institutional governance itself. As Marres has observed, this general approach to politics from ANT-based perspectives remains underdeveloped to the extent that theorists such as Latour or Michel Callon have criticized the subsumption of the objects of science by notions of method in traditional philosophies, but have not yet extended this same criticism to prescriptive accounts of democracy: "they do not criticize the widespread preoccupation with the "method" of democracy: participatory procedure, but outline such procedures themselves' (Marres, 'The Issues Deserve More Credit' 764). This is especially the case with the overarching commitment to 'the composition of a common world', since the entangled, risky and highly contingent objects of techno-science differ in crucial respects to the representative models of classical and republican theories of democracy.

Nevertheless, certain aspects of ANT methods are especially useful for understanding the political dimension of $A I R$ as media ecology. The project's ontological grounding consists in tracing multiplicities by contouring the practices, statements, the material and spatio-temporal states that define local area pollution, 'the matter-of-concern'. As in Latour's assemblage theory, AIR seems less concerned with questions of democratic procedure, than with following experimental approaches to specific, local controversies, and with diagramming how tensions arise from a multiplicity of forces, including those entities (breathers, pigeons) previously invisible within or excluded from representative arrangements that now return to spark disagreement and contestation. For Marres, similarly, issues should become the site of theoretical investigation for Dingpolitik, rather than attempts to renovate democratic institutions. Like $A I R$, her argument is for an adequate understanding of the hybrid composition of representative arrangements themselves. The implication is that the entanglements produced by modernity, such as air pollution, can now be widely sensed as failures of these institutions to effectively contain controversy, since ecological crises overflow the boundaries of their constituencies. As da Costa explains in relation to the collaborative work of biomedia activist projects, a fundamental characteristic of such work is a dialogue with those actors 'negatively affected' by research into biomedical, environmental and agricultural domains. The interest of Preemptive Media is, therefore, not focussed on 'the active involvement in changing people at play in taking command of the various institutions through which power is executed, but rather the radical undermining and redefinition of these institutions themselves' (da Costa 375). Indeed, the perceived need to open 'the hallowed halls of science' to collective negotiation is a task explicitly addressed by critical media artists in their move to engage with the life sciences (Critical Art Ensemble 59). Here lies a recurring question 
of how divisions of agency across distributed publics both incorporate and exclude - for Latour, the gaps formed in the combination of ecological thought with representational modes of political organisation. This is a central problem for reticular politics, since the nature-cultural studies approach to 'politics-in-the-making' is by no means innocent: it can be described as broadly inclusive, but is both directed and hierarchically composed. Emphasis needs to be placed, therefore, on the capacity to think through processes of assembling the collective, particularly on the 'potential injustice' of labelling enemies to the common world imagined by Latour (Politics of Nature 177).

In her reading, Marres proposes the concept of the 'issue network' to address these under-defined aspects of contemporary politics in a cosmopolitical frame. She argues, in particular, that 'issues' link together the fragments of the political left after the displacements of globalisation in the neoliberal era (i.e. the decoupling of the state from civil society), along with the distributive effects of techno-science and the rise of participatory media. In this situation, we might say that issues can serve as guides to the appropriate sites, subjects and forms of political activity (No Issue, No Public 5). There are three major claims at stake in this definition: actants should be understood as connected by a shared interest in an issue, rather than necessarily sharing 'thick' cultural bonds; that distributed politics entails the collective formatting of a concern in order to acquire resonance (as feedback) in public spheres; and that this process be conceived as operating in an open space of agonistic interactions (i.e. a terrain of conflict) (Marres, 'Net-Work Is Format Work' 5-12). While this last trait might be understood as linking non-governmental (tactical) politics to more formally institutional modes of deliberation, it should be noted that relational differences are still central to the enrolment of associations toward the articulation of controversies. That is, crucial distinctions are reinforced through asymmetries, by shifts in the distribution of resources and variable conditions across media ecologies of human and non-human entities, and by the role of expertise in the 'skills of the collective' (Latour, Politics of Nature 128-183). Indeed, such unevenness is a common feature of open and dynamic systems, a trait consistently identified by network analysis and the theorisation of techno-politics more generally (Terranova). With issue networks, these variations are recognised foremost as contributing to the formalisation of things - a terrain, however, that can only be sensed when politics is expanded out from 'pre-formatted' modes of procedural deliberation.

Significantly, in these various exchanges, in this experimentation with structure, Marres identifies a potential utility for 'creative practices' as conducive to developing contextual framings: 'an aesthetics that could ensure a place for issues in political discourses' ('Net-Work is Format Work' 14). In her account, decisions can only be based on quasi-objects, or partial beginnings that drive the reticulation of issues, but only in terms of an initial competence to sense 
their conditions of possibility. This coincides with the important caveat offered by Latour for the diplomatic significance of confronting entities previously rejected from the collective during the work of its composition (Politics of Nature 209-217). Aesthetics can, therefore, be seen as a key enabler for apprehending the movement of an actor-network, not in terms of a discipline making formal inquiries into 'beauty' or the 'sublime', but closer to what Geert Lovink and Anna Munster have described as a reinvigorated 'philosophical praxis investigating the very conditions of contemporary life' ('Distributed Aesthetics'). Here, projects such as Preemptive Media's AIR find a foothold in the organization of reticular politics and formulation of issues across distributed contexts, especially through their capacity to make inquiries into the status of relationships around us, accumulating invisibly, but garnering agency in an unresolved situation. To anticipate a place for the aesthetic is, in this sense, to highlight the vectors through which networks extend as emergent forums.

\section{Conclusion}

Atmosphere relates to a particular history of thought, to specific arrangements of sense, to matters-of-concern. In a recent short piece, Latour invokes a basic genealogy of air as a substance energised with particular meanings over time, brought into existence through historical lineages that now weigh on the present with ever-greater urgency. Drawing on the spherology of Peter Sloterdijk, he considers the example of chlorine gas used during warfare at Ypres in 1915, when a grey-green cloud of poisonous chemicals drifted over troops, forcing them to break ranks or suffocate as the oxygen was gradually removed from the trenches ('Airquakes'). This sudden sense of something being missing, of being reconfigured, is described as the moment when air entered 'a list of what could be withdrawn from us'. The event of things changing, of breakdown, conveys the political stakes of a co-fabricated reality between human and non-human. These are the moments when the fragility of the environment as 'life support' comes to the fore and becomes magnified. This experiential ontology, once repressed by attempts to frame nature by abstract representations and stable objects, is not founded on 'the scenography of empiricism', but on affect and movement:

Feeling is more roundabout; it's the slow realisation that something is missing. It resides, in a way, behind you, behind your back, or maybe even outside you in an untouchable greenish cloud-something you don't exactly understand and in charge of which people can only see through peripheral vision. (Latour, 'Air' 105)

Sensing from the periphery refers to a condition in which an environment is explicated and folded over as a process. Indeed, the very notion of perceiving the boundaries of this enveloping movement is congruent with the role of the 
network as a concept by which things momentarily glimpsed continually fall out-of-frame through their incorporation. Just as these forces of emergence and absorption must be opened out and properly understood in order for maintenance to occur, so too must our conception of political action through exchanges with complex socio-technological ensembles. These are the far-reaching consequences of the secondary materialism cited by Latour: whatever modes of support we rely on to spatialise fleeting conditions of a fragile, technical and public contention, ontogenetic or emergent forces are always at work. Projects like $A I R$ remind us of this through their grappling with issues: they maintain an objective incompleteness that remains central to the development of a reticular politics, and the capacity to face the problem of multiplicity.

Michael Dieter is a PhD candidate in the School of Culture and Communication at the University of Melbourne. His thesis, entitled Reticular Aesthetics, investigates trends in locative media, information visualisation and software art from the perspective of science and technology studies and political philosophy.

\section{Works Cited}

Beck, Ulrich. Risk Society: Towards a New Modernity. London: Sage, 1992.

Berry, Josephine. 'Bare Code: Net Art and the Free Software Movement.' DATA Browser 02-Engineering Culture: On the Author as (Digital) Producer. Ed. Geoff Cox and Joasia Krysa. New York: Autonomedia, 2005. 133-49.

Broeckmann, Andreas. 'Towards an Aesthetics of Heterogenesis.' Convergence 3.2 (1997): 48-58.

Critical Art Ensemble. Digital Resistance. New York: Autonomedia, 2001. <http://www.critical-art.net/books/digital/> Accessed 1 March 2009.

- The Molecular Invasion. New York: Autonomedia, 2001. $<$ http://www.critical-art.net/books/molecular/index.html > Accessed 1 March 2009.

da Costa, Beatriz. 'Reaching the Limit: When Art Becomes Science.' Tactical Biopolitics: Art, Activism, and Technoscience. Ed. Beatriz da Costa and Philip Kavita. Cambridge, MA: MIT Press, 2008. 365-86.

— and Philip Kavita. 'Introduction.' Tactical Biopolitics: Art, Activism, and Technoscience. Ed. Beatriz da Costa and Philip Kavita. Cambridge: MIT Press, 2008. xvii-xxii.

Deleuze, Gilles, and Félix Guattari. A Thousand Plateaus. Trans. Brian Massumi. Minneapolis: U of Minnesota P, 1987. 
Deleuze, Gilles, and Claire Parnet. Dialogues II. Trans. Hugh Tomlinson and Barbara Habberjam. London: Continuum, 2006.

Fuller, Matthew. Media Ecologies: Materialist Energies in Art and Technoculture. Cambridge, MA: MIT Press, 2004.

-. and Usman Haque. Urban Versioning System 1.0-Situated Technologies Pamphlet. New York: Architectural League of New York, 2008.

Guattari, Félix. Chaosmosis: An Ethico-Aesthetic Paradigm. Trans. Paul Bains and Julian Pefanis. Indiana: Indiana UP, 1995.

Latour, Bruno. 'The Aesthetics of Matters of Concern.' What is the Style of Matters of Concern? Two Lectures in Empirical Philosophy. Amsterdam: Van Gorcum, 2008. 16-32.

$<$ http://www.bruno-latour.fr/articles/article/97-STYLE-MATTERS-CONCERN.pdf> Accessed 1 March 2009.

-. 'Air.' Sensorium: Embodied Experience, Technology and Contemporary Art. Ed. Caroline A. Jones. Cambridge, MA: MIT Press, 2006. 105-07.

—. 'From RealPolitik to Dingpolitik or How to Make Things Public.' Making Things Public: Atmospheres of Democracy. Ed. Bruno Latour and Peter Weibel. Cambridge, MA: MIT Press, 2005. 14-43.

-. 'On Recalling ANT.' Actor Network Theory and After. Ed. John Law and John Hassard. Oxford: Blackwell Publishers, 1999. 15-25.

-. The Politics of Nature: How to Bring the Sciences into Democracy. Trans. Catherine Porter. Cambridge: Harvard UP, 2004.

-. Reassembling the Social: An Introduction to Actor-Network-Theory. Oxford: Oxford UP, 2005.

-. We Have Never Been Modern. Trans. Catherine Porter. New York: Harvester Wheatsheaf, 1993.

Lovink, Geert. 'An Insider's Guide to Tactical Media.' Dark Fiber: Tracking Critical Internet Culture. Cambridge, MA: MIT Press, 2002. 254-74.

-. and Anna Munster. 'Distributed Aesthetics, or, What the Network is Not.' Fibreculture Journal 7 (2005). <http://journal.fibreculture.org/issue7/issue7_munster_lovink.html> Accessed 1 March 2009.

Marres, Noortje. No Issue, No Public: Democratic Deficits after the Displacement of Politics. PhD Thesis, University of Amsterdam, 2005. <http://dare.uva.nl/document/17061> Accessed 1 March 2009.

- . 'Net-Work is Format Work: Issue Networks and the Sites of Civil Society Politics.' Reformatting Politics: Information Technology and Global Civil 
Society. Ed. Jodi Dean, Jon W. Anderson and Geert Lovink. London: Routledge, 2006. 3-18.

-. 'The Issues Deserve More Credit: Pragmatist Contributions to the Study of Public Involvement in Controversy.' Social Study of Science 37.5 (2007): 759-780.

Massumi, Brian. Parables for the Virtual: Movement, Affect, Sensation. Durham: Duke UP, 2002.

Sloterdijk, Peter. 'Airquakes.' Environment and Planning D: Society and Space 27.1 (2009): 41-57.

Thacker, Eugene. The Global Genome: Biotechnology, Politics, and Culture.

Cambridge: MIT Press, 2006.

Terranova, Tiziana. Network Culture: Politics for the Information Age. London: Pluto Press, 2004. 